\title{
Correction to: Molecular diversity of arbuscular mycorrhizal fungal communities across the gradient of alkaline Fe ore tailings, revegetated waste rock to natural soil sites
}

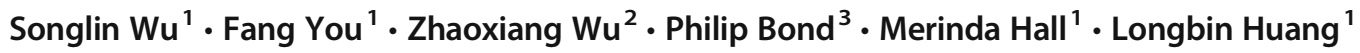 \\ Published online: 13 February 2020 \\ (C) Springer-Verlag GmbH Germany, part of Springer Nature 2020
}

\section{Correction to: Environmental Science and Pollution Research https://doi.org/10.1007/s11356-020-07780-x}

The correct presentation of the Acknowledgments is shown in this paper.

The authors thank the Australian Centre for Ecogenomics in the University of Queensland for conducting Illumina sequencing. The work is financially supported by Australia Research Council Linkage Project (LP160100598), Karara Mining limited, and The Botanic Gardens and Parks Authority (BGPA) and UQ ECR funding (613767).

Publisher's note Springer Nature remains neutral with regard to jurisdictional claims in published maps and institutional affiliations.

The online version of the original article can be found at https://doi.org/ 10.1007/s11356-020-07780-x

Longbin Huang

1.huang@uq.edu.au

1 Centre for Mined Land Rehabilitation, Sustainable Minerals Institute, The University of Queensland, Brisbane, Queensland 4072, Australia

2 Jiangxi Engineering and Technology Research Center for Ecological, Remediation of Heavy Metal Pollution, Institute of Biological,

Resources, Jiangxi Academy of Sciences, Nanchang 330096, China

3 Advanced Water Management Centre, The University of

Queensland, Brisbane, Queensland 4072, Australia 